\title{
The Usage of ROOT in Analyzing Gamma-rays with Covell and Total Peak Area Methods
}

\author{
Ilker Can Celik ${ }^{1 *}$ \\ 1* Harran University, Faculty of Art and Science, Departmant of Physics, Sanliurfa, Turkey, (ORCID: 0000-0002-2320-6584), ilkercan0066@harran.edu.tr
}

(1st International Conference on Applied Engineering and Natural Sciences ICAENS 2021, November 1-3, 2021)

(DOI: 10.31590/ejosat.997976)

ATIF/REFERENCE: Celik, I. C. (2021). The Usage of ROOT in Analyzing Gamma-rays with Covell and Total Peak Area Methods. European Journal of Science and Technology, (28), 285-289.

\begin{abstract}
ROOT is a framework for a physicist to save data, to access the data, to mine the data and to publish results in a graphical interface. As a gamma ray spectroscopist, one of the most useful features of it is to estimate and to calculate the integral of a peak area. When this is done, not always these peaks can be isolated easily. Also, the methods differ the results of the total counts under the peak areas. Regardless of the detector types, the written $\mathrm{C}++$ codes for ROOT can be easily implemented and adjusted for any peak situation. As an example, Maestro, which is a multichannel analyzer (MCA) emulation software package, is one of the most common software for $\mathrm{NaI}$ detector type. However, the users of this package mostly do not know the details of its procedure to collect and integrate the total counts for each individual gamma-ray. For that reason, it will be useful to indicate the comparisons for an experimental data by using Covell and Total Peak Area (TPA) methods between ROOT and Maestro.
\end{abstract}

Keywords: ROOT, Maestro, Covell Method, Total Peak Area Method, C++ Codes

\section{Covell ve Toplam Pik Alanı Methodlarıyla Gama Işınlarının Analizleri Yapılırken ROOT Uygulamasının Kullanımı}

\begin{abstract}
Özet
ROOT, bir fizikçi için veri depolamak, veriye ulaşmak, veriyi araştırmak ve sonuçları grafiksel bir arayüzle ortaya koymaya yarayan bir çalışma alanıdır. Gama ışını spektroskopisi uzmanı olarak, ROOT uygulamasının en yararlı özelliklerinden biri, bir gama 1şını pik alanını tahmin edebilmesi ve hesaplayabilmesidir. Bu işlem yapılırken, her zaman pikler kolaylıkla izole edilemezler. Ayrıca, seçilen yönteme göre toplam pik alanı sonuçları da farklılık gösterecektir. Dedektör tipine bağlı olmaksızın, ROOT için yazılmış C++ kodları herhangi bir pik durumu için kolaylıkla uygulanabilmekte ve ayarlanabilmektedir. Örneğin, çok kanallı analizör örneği olan Maestro yazılım paketi, NaI dedektörleri için en çok kullanılan yazılımlardan biridir. Buna rağmen, bu yazılımın kullanıcıları her bir gama ışını sayım sayısının nasıl toplandığını ve hesaplandığını detaylı bir şekilde bilmemektedir. Bu yüzden, deneysel bir veri üzerinden Covell ve Toplam Pik Alanı metodlarının karşılaştırmasını ROOT ve Maestro arasında yapmak faydalı olacaktır.
\end{abstract}

Anahtar Kelimeler: ROOT, Maestro, Covell metodu, Toplam Pik Alanı metodu, C++ kodları.

\footnotetext{
*Corresponding Author: ilkercan0066@harran.edu.tr
} 


\section{Introduction}

Before getting into any calculations, it is better to mention about statistics in counting of gamma-rays in specific. Statistics are unavoidable naturally occurring mathematical concept which nuclear physicists will encounter. In most laboratories, nuclear physicists mostly work on a radioactive substance that decays randomly. Moreover, this randomness provides a statistical approach by nature. Thus, all measurements can be just an estimate of a decay rate. In the simplest view, one detection requires a radioactive material, a detection system, a tool of counting, and a time period. After measuring the rate in the events, this can be related directly and proportionally to the number of atoms in the source to define the activity of a source. Despite these aspects, only the integration of peak area measurements (counts) will be calculated here. By doing so, relevant background subtraction and fitting methods will be presented respectively. The tools for investigation in this study were Maestro software calculations (A65-B32 Software's User's Manual, 2020), Covell method (Gilmore, 2008; Heydorn \& Lada, 1972; Covell, 1959), Total Peak Area (TPA) method (Covell, 1959; Loska, 1987), and the ROOT coding via fittings.

\section{Methodology and Analysis}

Over the years, $\gamma$-ray spectroscopists have used some simple and complicated algorithms to integrate the peak areas under the peak of interest (POI). However, the Covell and TPA methods will be under investigation in this study. Their results will be compared with the MAESTRO software calculations and the result of ROOT fits. As an experimental data to apply those calculations and fits, $661 \mathrm{keV} \gamma$-ray peak of $137 \mathrm{Cs}$ and $\gamma$-ray peaks of $60 \mathrm{Co}$ at $1173 \mathrm{keV}$ and $1332 \mathrm{keV}$ were used. For the analysis, the details of the point sources were irrelevant.

Around the world, $\mathrm{NaI}(\mathrm{Tl})$ detectors are one of the most common ones in university laboratories due to their affordable cost. These detectors use mostly Maestro-32 software on Windows with MCA emulators embedded in them. This MCA emulates, sorts and counts events in real time during any experiment. Their sorting relies on some properties of these events. For this study, the only detail we should know is that these events were grouped inside the bins which were shown as channels. The multichannel analysis of the event is called pulseheight analysis (PHA) whose signals are triggered every time when a detector has hit via $\gamma$-rays. The characteristic part of these heights or voltages seen on the systems is that they are proportional to the $\gamma$-ray energies. Thus, the hits will be categorized by their heights. The detection system has also analog to digital converter (ADC) which translates the analog signal to a digital representation in the channel number. Therefore, each channel corresponds to a pulse height or a voltage. MCA commits them into a memory as the distribution of pulses in ascending energy order while the pulses of $\gamma$-rays arrive to a detector. In the meantime, ADC channels also store similar signals, but not necessarily identical ones. This complete picture is, then, called spectrum. For the $\gamma$-ray count analysis, the data should be saved, for simplicity, as a spectrum with equal bin width. Additionally, this structure can be called histogram of interest. Specifically, the analyzed spectra will remain uncalibrated in terms of energy in this study. The methods of integrations for counting the $\gamma$-rays will be given as following respectively: Maestro calculations, Covell and TPA method calculations, and ROOT fit results.

Figure 1a shows the representation of Maestro software's calculations. For the uncalibrated spectrum, software gives some information: the channel centroid, FWHM in channels, gross area, net area, and the net-area uncertainty for the region of interest (ROI) marked by the user according to the manual (A65-B32 Software's User's Manual, 2020). The program deducts the calculated background channel by channel. Then, it tries the leastsquares fit of a Gaussian (Squires, 2001; Baedecker \& Grossman, 1989) function to the net area. If successful, the fitted function will give the centroid. If not, the peak position was decided at where the highest number of counts within the peak limits. Linear interpolation between the background-subtracted channels will give the reported widths. Because of the software's version, there was no fit on display during the analysis. The Fig. 1a indicates the low (l) and high limit (h) of the ROI, count number as $\mathrm{C}_{\mathrm{i}}$ at $i$ th channel, $A_{M}$ as the net area and $G_{M_{a d j}}$ as the adjusted gross area in the same ROI. The subscript $M$ will be used for Maestro software calculations from this point onwards for clarity. The background $\left(\mathrm{B}_{\mathrm{M}}\right)$ was accepted as the flat area of a trapezium, given by $B_{M}=\left(\sum_{i=l}^{l+2} C_{i}+\sum_{i=h-2}^{h} C_{i}\right) \times \frac{(h-l+1)}{6}$ under the ROI. The nominator of $(h-l+1)$ represents the total ROI width. The adjusted background area, however, was defined by $B_{M a d j}=$ $B_{M} \times \frac{(h-l+1-6)}{(h-l+1)}$ as shown in Fig. 1a. Whilst the gross area was equal to $G_{M}=\sum_{i=l}^{h} C_{i}$, the adjusted gross area was formulated by $G_{M_{\text {adj }}}=\sum_{i=l+3}^{h-3} C_{i}$. Thus, the net area inside the width of "h-1-6" bins was calculated by $A_{M}=G_{M a d j}-B_{M_{a d j}}$. The uncertainty in the net area was also calculated by the square root of the addition of the squares of the uncertainty in the weighted error of the adjusted background area and the adjusted gross area. Briefly, it was represented by $\sigma_{A_{M}}=\sqrt{G_{M_{a d j}}+\left[B_{M_{a d j}} \times\left(\frac{(h-l+1-6)}{6}\right)\right]}$.

In early days of $\gamma$-ray spectroscopy, Covell Method was also used in NaI scintillation spectra, but in a different way. When using $\mathrm{NaI}$ detectors with low resolution, overlapping peaks might be more frequent in comparison to high resolution high purity Germanium detectors (HPGe). This issue brought the limitation criteria on $\gamma$-ray analysis in scintillation detectors. Because of peak interferences, it was needed to restrict the whole range of a Gaussian peak of a $\gamma$-ray. However, the same width (portion) of the peaks would be used throughout the analysis for consistency to retrieve the entire data due to compensation done before. By knowing the ratio of the integrated areas from standard deviations, the analysis would be made more efficient (Squires, 2001). In the peak area integration procedure on the other hand, the Covell method was based on locating the peak centroid first and then limiting the peak range equally on both sides of the peak's centroid channel (Heydorn \& Lada, 1972). This was simply shown in Fig. 1b. It's stated by the Kaj and Witold that this method gave accurate results when the peak was single and isolated with a background represented by a straight line. They also said that the precision of the peak area integration relies on the channel range under the peak. However, we will use Covell method for overlapping peaks with a restricted ROI. In addition, Covell method assumes no correlation among channels in the spectrum, and this affects the calculation of the variance. In Fig. $1 \mathrm{~b}$, initial version of the Covell method was shown. The background level estimation in the Fig. $1 \mathrm{~b}$ was done by using only 
one blacked bin on both side of the lower (L) and upper (U) limits of the peak in

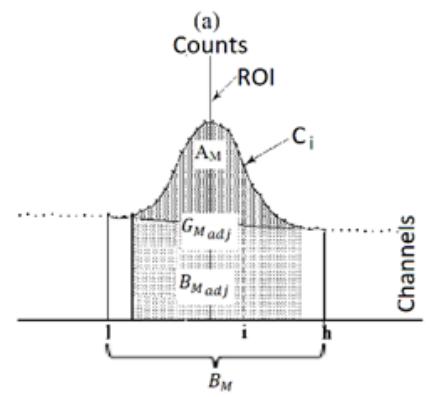

(b)

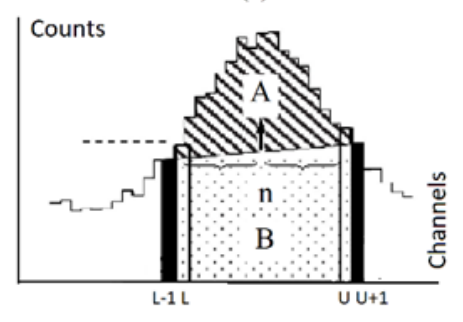

(c)

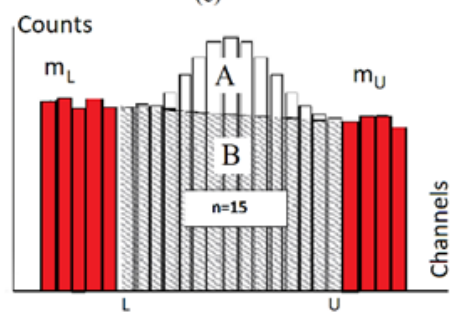

Figure 1: Figure 1a indicates the area separation in Maestro software. Figure 1b shows the different areas with dotted and stripped patterns for undeveloped versions of Covell and TPA methods. However, Fig. 1c represents the improved version of Covell and TPA methods.
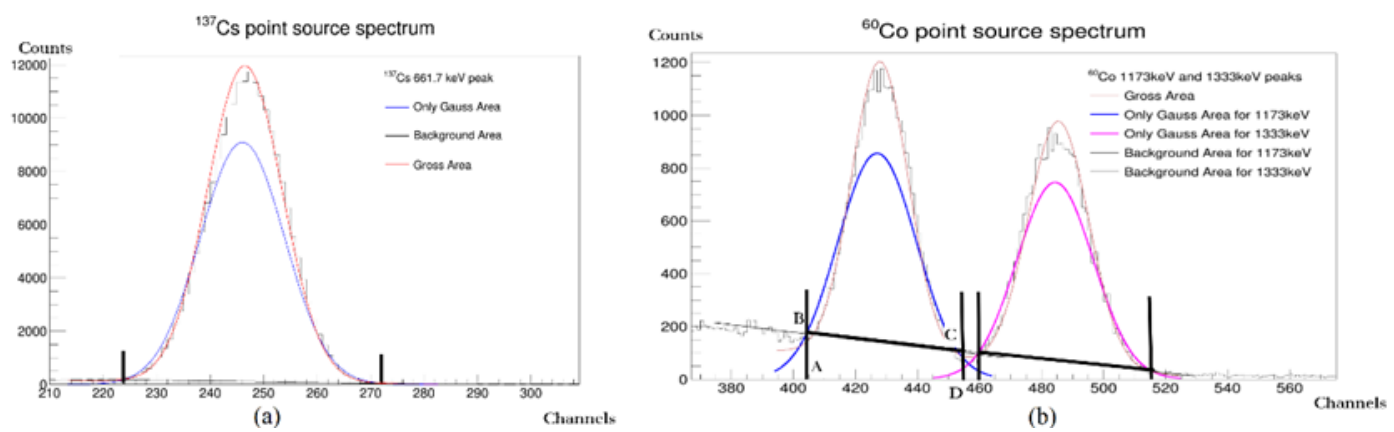

(b)

Figure 2: Figure indicates the portions of uncalibrated $\gamma$-ray spectra for ${ }^{60} \mathrm{Co}$ and ${ }^{137} \mathrm{Cs}$ point sources. Peak energies in these point sources were listed on the top right of the legends in ROOT canvas. Total channels used here were 1024, and spectra had 1 bin resolution per channel. Vertical lines were just to visualize the confidence limits for the user's input to initialize the code.

this example. Therefore, background (B) beneath the POI could be calculated by the equation of $B=n \times \frac{\left(C_{L-1}+C_{U+1}\right)}{2}$ where $\mathrm{C}$ represented the counts of their corresponding bins as indicated. The letter $\mathrm{n}$ stands for the total number of channels under the POI. Whilst gross $(\mathrm{G})$ area of the peak equals to $G=\sum_{i=L}^{U} C_{i}$, the subscript of $i$ stands for the $i$ th channel. The net peak area (A) is given by the following: $A=G-B=\left(\sum_{i=L}^{U} C_{i}\right)-[n \times$ $\left.\frac{\left(C_{L-1}+C_{U+1}\right)}{2}\right]$. Additionally, the variance of $\mathrm{A}, \operatorname{var}(\mathrm{A})$, is equal to $\sum_{i=L}^{U} C_{i}+\left[\frac{n^{2}}{(2)^{2}} \times\left(C_{L-1}+C_{U+1}\right)\right]$ due to the rule of $\operatorname{var}(\mathrm{kx})=k^{2} \operatorname{var}(x)$. The uncertainty $\left(\sigma_{A}\right)$ then becomes $\sqrt{\operatorname{var}(A)}$. This method indicates that the background area can only be estimated by the adjacent counts to the ROI. Meanwhile, the sources of possible background counts in $\gamma$-ray spectroscopy will not be mentioned in this study. However, be aware that the uncertainty of the background can affect the total uncertainty of the peak area measurements.

On the contrary, TPA (Gilmore, 2008; Loska, 1987) method was used for an isolated single peak in this study. The representation can be seen in Fig. 1c. It was known that the reduction in uncertainty after adding extra channels for background calculation faded away after 3 or 4 channels. In practice, more than 9 or 10 channels had no beneficial use in the absence of neighbouring peaks (Gilmore, 2008). More channels to estimate the background makes the calculations more precise, so the mean count per channel under the peak becomes less uncertain. It was also mentioned by Baedecker that TPA method was less sensitive to the effect of errors due to peak broadening at the time of higher rates in counting the $\gamma$-rays in comparison to Covell method (Baedecker \& Grossman, 1989). However, this will not be proven here. Since the adjacent peaks are more frequent in $\gamma$-ray spectroscopy with the advent of high-resolution detectors, flexible limits on choosing the ROI become the inevitable rules of any analysis. For instance, background estimation area can span different number of bins (channels) for the lower $\left(\mathrm{m}_{\mathrm{L}}\right)$ and upper part $\left(\mathrm{m}_{\mathrm{U}}\right)$ (Gilmore, 2018; Quittner, 1969). Therefore, previous formula for $\mathrm{B}$ was revised as $\mathrm{B}=n \times$ $\frac{\left(\sum_{L-m_{L}}^{L-1} C_{i}+\sum_{i=U+1}^{U+m_{U}} C_{i}\right)}{m_{L}+m_{U}}$. Gross area, however, remained the same. Since the net area (A) was calculated as $A=G-B$, the variance of the A could also be calculated as $\operatorname{var}(\mathrm{A})=\operatorname{var}(\mathrm{G})+\operatorname{var}(\mathrm{B})=\left(\sum_{i=L}^{U} C_{i}\right)+\left[\left(\frac{n^{2}}{\left(m_{L}+m_{U}\right)^{2}}\right) \times\right.$ $\left.\left(\sum_{L-m_{L}}^{L-1} C_{i}+\sum_{i=U+1}^{U+m_{U}} C_{i}\right)\right]$. Then, the true standard deviation (the uncertainty) can be summarized by $\sigma_{A}=\sqrt{\operatorname{var}(A)}=$ $\sqrt{G+\left(B \times \frac{n}{m_{L}+m_{U}}\right)}$ by the rule of $\operatorname{var}(\mathrm{G})+\operatorname{var}(\mathrm{B})=\operatorname{var}(\mathrm{G}+\mathrm{B})$ in the case of no correlation between the terms [2].

In Fig.2, ROOT fits were applied on the same experimental data of ${ }^{60} \mathrm{Co}$ and ${ }^{137} \mathrm{Cs}$ point sources. The peak energies of 661.7 $\mathrm{keV}, 1173 \mathrm{keV}$ and $1333 \mathrm{keV}$ were shown at their corresponding channel numbers. Whilst red lines mark the gross count $(\mathrm{G})$ region, blue lines show the net signal area after background (B) 
Table 1: In this study, the Maestro software's outputs in the first column were regarded as the reference, but the calculations of Maestro, TPA and Covell methods as stated in the text were also performed by the ROOT coding on the data. They were marked by R suffix. Lastly, the ROOT fit results were listed for a comparison.

\begin{tabular}{|c|c|c|c|c|c|c|c|c|c|c|c|c|}
\hline & ${ }^{37} \mathrm{Cs} 661$ & & & & ${ }^{60} \mathrm{Co} 11$ & $\mathrm{keV}$ & & & ${ }^{60} \mathrm{Co} 13$ & $\mathrm{keV}$ & & \\
\hline $\begin{array}{l}\stackrel{\infty}{\Xi} \\
\stackrel{\Xi}{0}\end{array}$ & 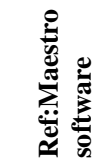 & 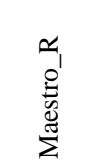 & 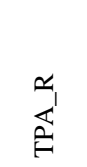 & 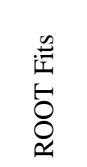 & 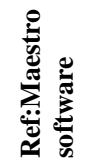 & 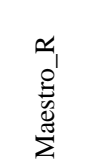 & $\begin{array}{l}\alpha \\
\overline{0} \\
\overrightarrow{0} \\
0\end{array}$ & 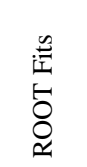 & 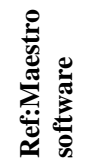 & 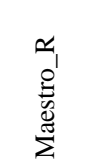 & $\begin{array}{l}\mathcal{L} \\
\overline{0} \\
\overrightarrow{0} \\
\dot{0}\end{array}$ & 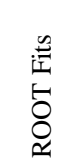 \\
\hline Centroid_Bin & 247 & 248 & 248 & - & 429 & 429 & 429 & - & 484 & 483 & 483 & - \\
\hline Centroid_Fit & - & - & - & 246.7 & - & - & - & 428.05 & - & - & - & 484.7 \\
\hline Peak_Limits & 230-266 & $230-266$ & $230-266$ & - & $408-450$ & $408-450$ & $408-450$ & - & $461-509$ & $461-509$ & $461-509$ & - \\
\hline $\mathrm{n}$ & 37 & 37 & 37 & - & 43 & 43 & 43 & - & 48 & 48 & 48 & - \\
\hline $\mathrm{m}_{\mathrm{L}}$ & 3 & 3 & 4 & - & 3 & 3 & 3 & - & 3 & 3 & 3 & - \\
\hline $\mathrm{m}_{\mathrm{U}}$ & 3 & 3 & 4 & - & 3 & 3 & 3 & - & 3 & 3 & 3 & - \\
\hline$\sigma_{G}$ & - & - & - & 22742.2 & - & - & - & 3266 & - & - & - & 295.8 \\
\hline $\mathrm{G}_{\mathrm{adj}}$ & 205598 & 201546 & - & - & 28663 & 27576.6 & - & - & 24757 & 24124.1 & - & - \\
\hline B & - & 29563 & - & 62557.3 & - & 8406.5 & - & 9666.4 & - & 5618.7 & - & 5736.6 \\
\hline$\sigma_{B_{M}}$ & - & - & - & 250.3 & - & - & - & 98.37 & - & & - & 75.78 \\
\hline$B_{\text {adj }}$ & - & 24793.8 & 10804 & - & - & 7240.7 & 6256.5 & - & - & 4935.6 & 3221.75 & - \\
\hline$A_{n}$ & 173494 & 176752 & 195334 & 145510 & 20242 & 20335.8 & 22465.5 & 20051 & 19212 & 19188 & 21566.2 & 19391.8 \\
\hline$\sigma_{A_{n}}$ & 582 & 574.61 & 505.7 & 520.2 & 268 & 268.94 & 309.59 & 198.5 & 242 & 244.1 & 253.71 & 175.7 \\
\hline FWHM_Fit & 15.92 & 17 & 17 & 17.003 & 21.23 & 24.51 & - & 24.51 & 22.8 & 25.93 & - & 25.9 \\
\hline
\end{tabular}

subtraction. The background increases as the $\gamma$-ray energies increase, and this became apparent between Figure $2 \mathrm{a}$ and $2 \mathrm{~b}$ for ${ }^{137} \mathrm{Cs}$ and ${ }^{60} \mathrm{Co}$ peaks. The representation of background as trapezoid, for example, was framed by A,B,C, and D letters in Fig. $2 \mathrm{~b}$. In ROOT, outcomes were based on the fit results on the data. Therefore, total function for fitting was firstly defined as the sum of Gaussian and $1^{\text {st }}$ order polynomial functions for the consistency with previous calculations. This sum function was, then, fitted on a data to retrieve its parameters. Additionally, the user-controlled confidence limits, coverage ratio and coverage factor were introduced in the code for peak area integration. To get the net count (A), gross count number $(G)$ deduced from the background counts (B) under the same ROI by using pre-defined integral function in ROOT. This strategy was different than the Covell and TPA methods. The graphical interface in Fig. 2 also helps the user to decide about ROI, POI, and background limits in the initialization stage for fittings. User-set coverage ratio was used to retrieve the whole counts corresponding to the total counts beneath the POI (Ellison at al., 2009). It's because the covered ROI might not cover $100 \%$ of the peak all the time. By the individual errors in gross and background counts, the uncertainty of $\mathrm{A}$ was calculated by $\operatorname{var}(\mathrm{A})=\operatorname{var}(\mathrm{G})+\operatorname{var}(\mathrm{B})$ and $\sigma_{A}=$ $\sqrt{\operatorname{var}(A)}$ for the case of $\mathrm{A}=\mathrm{G}-\mathrm{B}$.

\section{Results and Comments}

As a result, the methods of Covell and TPA were similar regarding the formulation. However, their applications were different as explained. As the TPA method could retrieve roughly
$99.9 \%$ area statistically with $3 \sigma$ confidence limit by coverage factor of 3 , it was hard for the Covell method to extend the limits that much in the case of interfering $\gamma$-ray peaks. Note that the confidence limit was defined by the coverage factor multiply the standard deviation $(\sigma)$. Therefore, the Covell method required additional coverage ratio to insert into its calculations. According to Table 1 , net area results gave approximately $2 \%$ and $13 \%$ higher values in Maestro_R and TPA_R but 16\% lower for the ROOT fits in comparison to Maestro software in the case of ${ }^{137} \mathrm{Cs}$ example. For ${ }^{60} \mathrm{Co}$ peak at $1173 \mathrm{keV}$, net counts were approximately $0.4 \%$ and $11 \%$ higher values in Maestro_R and Covell R but $0.9 \%$ lower for the ROOT fits in comparison to Maestro software. Lastly, net area for ${ }^{60} \mathrm{Co}$ peak at $1332 \mathrm{keV}$ appeared approximately $0.1 \%$ and $12 \%$ higher values in Maestro_R and Covell_R, and also $0.9 \%$ higher for the ROOT fits beside Maestro software. The proximity to the reference values is high in Maestro_R and ROOT fts. However, TPA or Covell methods presented around $11 \%$ closeness to Maestro software's results. This only means more adaptations in calculations and better fit functions, such as 2nd order polynomials for the background, in ROOT analysis could be implemented in the analysis. Also, different integration methods could be added in ROOT coding for comparisons.

\section{References}

A65-B32 Software's User's Manual. Ortec Part No. 777800. Available: https://www.ortec-online.com//media/ametekortec/manuals/a65-mnl.pdf [Access on: 1th September 2020]. 
Baedecker, P.A. \& Grossman, J.N. The computer analysis of high resolution gamma-ray spectra from instrumental activation analysis experiments. (Report series number: 89-454). U.S. Geological Survey, Reston, Virginia 22092. (1989). p. 1-55. https://doi.org/10.3133/ofr89

Covell, D.F. Determination of gamma-ray abundance directly from the total absorption peak. Analytical Chemistry, 31(11). (1959, November). p. 1785-1790. https://doi.org/10.1021/ac60155a027

Ellison, S.L.R., Barwick, V. J., Farrant, \& T.J. D. Practical statistics for the analytical scientist: a bench guide (valid analytical measurement). Thomas Graham House, Science Park, Milton Road, Cambridge CB4 0WF, UK: The Royal Society of Chemistry. (2009). p. 25.

Gilmore, G. R. Practical Gamma Ray Spectrometry. 2nd Edition. Warrington, UK: John Wiley and Sons, Ltd. 2008. p. 101-131.

Heydorn, K. \& Lada, W. Peak boundary selection in photopeak integration by the method of Covell. Analytical Chemistry, 44(14) (1972). p. 2313-2317. https://doi.org/10.1021/ac60322a006

Loska, L. A modification of the "total peak area" (TPA) method for gamma ray spectra. International journal of Radiation Applications and Instrumentation. Part A. Applied Radiation and Isotopes, 39 (6). (21, December, 1987). p. 475-477. https://doi.org/10.1016/0883-2889(88)90192-X

Squires, G.L. Practical Physics 4th Edition. Cambridge University Press. (2001). p.18-26.

Quittner, P. Peak area determination for Ge(Li) detector data. Nuclear Instruments and methods, 76. (1969, May, 27). p. 115-124. https://doi.org/10.1016/0029-554X(69)90299-7 